\title{
Quality Measurement of Serious Illness Communication: Recommendations for Health Systems Based on Findings from a Symposium of National Experts
}

\author{
Justin J. Sanders, MD, MSc, ${ }^{1-4}$ Joanna Paladino, MD,1-3 Erica Reaves, MPP, \\ Hannah Luetke-Stahlman, MPA, ${ }^{6}$ Rebecca Anhang Price, PhD, ${ }^{7}$ Karl Lorenz, MD, MHS, ${ }^{8}$ \\ Laura C. Hanson, MD, MPH, ${ }^{9,10}$ J. Randall Curtis, MD, MPH, ${ }^{11,12}$ Diane E. Meier, MD, ${ }^{13,14}$ \\ Erik K. Fromme, MD, MCR, ${ }^{1-4}$ and Susan D. Block, MD ${ }^{1-4,15}$
}

\begin{abstract}
Background: Communication between clinicians and patients fundamentally shapes the experience of serious illness. There is increasing recognition that health systems should routinely implement structures and processes to assure high-quality serious illness communication (SIC) and measure the effectiveness of their efforts on key outcomes. The absence, underdevelopment, or limited applicability of quality measures related specifically to SIC, and their limited application only to those seen by specialist palliative and hospice care teams, hinder efforts to improve care planning, service delivery, and health outcomes for all seriously ill patients.

Objective: We convened an expert stakeholder symposium and subsequently surveyed participants to consider challenges, opportunities, priorities, and strategies to improve quality measurement specific to SIC.

Results: We identified several barriers and opportunities to improving quality measurement of SIC. These include issues related to the definition of SIC, methodological challenges related to measuring SIC and related outcomes, underutilization of technologies that can facilitate measurement, and measurement development, and dissemination.

Conclusions: Patients, clinicians, and health systems increasingly align around the importance of highquality communication in serious illness. We offer recommendations for various stakeholder groups to advance SIC quality measurement. Enthusiasm and a sense of urgency among health systems to drive and measure communication improvements inform our proposal for a set of example measures for implementation now.
\end{abstract}

Keywords: communication; expert stakeholders; quality measures; serious illness

${ }^{1}$ Harvard Medical School, Boston, Massachusetts

${ }^{2}$ Ariadne Labs, Brigham and Women's Hospital, Harvard T.H. Chan School of Public Health, Boston, Massachusetts.

${ }^{3}$ Department of Medicine, Brigham and Women's Hospital, Boston, Massachusetts.

${ }^{4}$ Department of Psychosocial Oncology and Palliative Care, Dana-Farber Cancer Institute, Boston, Massachusetts.

${ }^{5}$ Harvard T.H. Chan School of Public Health, Boston, Massachusetts.

${ }^{6}$ Cerner Corporation, Kansas City, Missouri.

${ }^{7}$ RAND Corporation, Arlington, Virginia.

${ }^{8}$ Division of Palliative Care, Palo Alto VA Health Care System, Stanford University School of Medicine, Palo Alto, California.

${ }^{9}$ Cecil G. Sheps Center for Health Services Research, University of North Carolina, Chapel Hill, North Carolina.

${ }^{10}$ Division of Geriatric Medicine and Palliative Care Program, University of North Carolina Chapel Hill, Chapel Hill, North Carolina.

${ }^{11}$ Division of Pulmonary, Critical Care, and Sleep Medicine, Department of Medicine, University of Washington, Harborview Medical Center, Seattle, Washington.

${ }^{12}$ Cambia Palliative Care Center of Excellence, University of Washington, Seattle, Washington.

${ }^{13}$ Center to Advance Palliative Care, New York, New York.

${ }^{14}$ Brookdale Department of Geriatrics and Palliative Medicine, Icahn School of Medicine at Mount Sinai, New York, New York.

${ }^{15}$ Department of Psychiatry, Brigham and Women's Hospital, Boston, Massachusetts.

Accepted September 18, 2019. 


\section{Background}

C OMMUNICATION between a clinician* and a patient and their family or other surrogates fundamentally shapes the experience of serious illness. Illnesses have been defined as serious when they impart a high risk of mortality and contribute to negative effects on patient or caregiver quality of life. ${ }^{1-3}$ A growing body of evidence supports the notion that effective communication with those who have serious illness improves population health outcomes, patient (and family) experience, and health care spending ${ }^{4-7}$; and that ineffective communication may contribute to clinician burnout, dissatisfaction, and poor care. ${ }^{8-10}$ We use the term serious illness communication (SIC) to describe conversations between clinicians and patients with serious illness about their goals, values, and priorities.

Timely, high-quality SIC enables and enhances decision making and care planning by fostering patients' prognostic awareness and translating what matters most to patients into care recommendations. Perhaps, as a result, SIC is associated with better quality of life and care, $, 4,6,11,12$ and has been shown to reduce anxiety and depression. ${ }^{13}$ Conversely, absent, delayed, or low-quality communication may result in patient suffering. ${ }^{14}$ There is increasing recognition that health systems should routinely implement structures and processes to assure high-quality SIC and measure the effectiveness of their efforts on key outcomes.

The communities of researchers who study and care for patients with serious illness have developed measures of care quality, including communication. Efforts by those in the hospice and palliative care communities to measure and demonstrate the quality of palliative care have led to quality measure sets for communication and relevant outcomes, such as Assessing Care of Vulnerable Elders (ACOVE) ${ }^{15}$; data registries, such as the Global Palliative Care Quality Alliance $^{16}$ and the Palliative Care Quality Network ${ }^{17}$; and quality frameworks, such as American Academy of Hospice and Palliative Medicine (AAHPM) Measuring What Matters. ${ }^{18}$ Whether they are well implemented, as in hospice, or less so, as in broader palliative care or serious illness care, existing measures incompletely capture SIC components and outcomes. Existing quality measures focus on aspects of SIC that overlap with advance care planning (ACP), such as identifying surrogates or decisions about life-sustaining treatment, but omit measures of the quality and depth of communication. This limitation reflects the state of the science rather than a failure of inclusion. ${ }^{19}$ While critical to advancing quality of care, these measure sets typically apply only to patients who access specialized palliative and hospice care services, rather than the broader population of patients with serious illness. Experts have begun to articulate and address the challenges inherent to providing and measuring quality care for seriously ill persons and their families, among them, assessing high-quality communication. ${ }^{20,21}$ The absence, underdevelopment, or limited applicability of quality measures related specifically to SIC, and their limited application only to those seen by specialist palliative and hospice care teams, hinder efforts to improve care planning, service delivery, and health outcomes for all seriously ill patients.

*We use the word clinician to cover a range of clinical professions, including physicians, advance practice providers, social workers, and nurses.
SIC warrants distinction as a focus of quality measurement due to (1) the risk of suffering in serious illness, (2) the potential for communication to mitigate this suffering, and (3) the unique implementation challenges inherent to such communication, including clinician avoidance due to training deficits and difficult emotions. In addition, while ACP occurs in multiple settings, and therefore warrants attention in primary care or community settings, absent or poor quality SIC can undermine even the best ACP initiated in the community. By contrast, high-quality SIC can effectively translate ACP started in the community into care plans that reflect patients' goals, values, and preferences.

The Serious Illness Care Program at Ariadne Labs, a joint health system innovation center at Brigham and Women's Hospital and the Harvard T.H. Chan School of Public Health, convened a symposium of expert stakeholders to clarify and prioritize quality measurement constructs relevant to SIC. In this article, we describe the findings from this symposium and related activities, to recommend strategic and measurement priorities for health systems seeking to improve quality communication for persons with serious illness.

\section{Methods}

We employed a four-stage approach to clarify and prioritize quality measurement constructs relevant to SIC.

First, using PubMed and snowball sampling, we conducted a literature review to identify existing quality measurement domains and instruments.

Second, we hosted a two-day symposium with 26 relevant stakeholders, including leaders in palliative care, public health and health services research, health system administration, health policy, measurement science, and representatives from health care information technology (IT) vendors and the Centers for Medicare \& Medicaid Services. In preparation for this symposium, we articulated a conceptual framework informed by Donabedian's structure-processoutcome quality of care model to consider system-, clinician-, and patient-level factors ${ }^{22}$ and the quadruple aim of health care. $^{23}$ While measures of patient experience are important outcomes of SIC processes, we made a decision to separate measures of SIC experience from other outcome measures. We did so because they relate specifically and explicitly to the experience of SIC and are therefore qualitatively different from outcome measures (e.g., anxiety, depression, or quality of life) whose measurement may be impacted by other care processes or illness factors. Using detailed notes from four dedicated note takers, we identified and summarized key discussion themes.

Third, we analyzed gaps between communication-relevant domains of quality measurement identified at the symposium and existing research instruments and quality process and outcome measures used to assess serious illness care.

Finally, we surveyed participants after the symposium to clarify potential priorities based on findings in the gap analysis. We did so by asking them to (1) rate the degree to which they agreed or disagreed that each of a set of symposiumidentified structure, process, experience, and outcome measures could improve care for patients with serious illness; and (2) rank the importance of existing measures or constructs for inclusion in existing measure sets (e.g., Consumer Assessment of Healthcare Providers and Systems $\left[\mathrm{CAHPS}^{\circledR}\right]$ ) or development as quality measures, respectively. 


\section{Results}

\section{Measurement scan}

Our measurement scan yielded a set of process, patient experience, and outcome measures. We organized outcome measures into patient-reported outcomes (e.g., the degree to which a patient felt informed), patient-specific outcomes (e.g., goal-concordant care), caregiver outcomes (e.g., involvement in care decisions), and population-level outcomes (e.g., utilization measures). Supplementary Table S1 includes representative measures by domain. Communication process measures predominantly focused on documentation of treatment preferences or of surrogate decision makers, with less emphasis on goals of care discussion or documentation. Many of these measures are vaguely defined, without clear guidance about how to measure. For example, Advance Care Plan (NQF 326) is not clearly defined in the measure language. $^{24}$ In addition, National Quality Forum (NQF) Preferred Practice 18 is not clear in its definition of "regular patient and family conferences." The only mention of patient goals and values, a key element of SIC, is in a bereaved family survey. No measures addressed discussion about or documentation of goals and values.

\section{Symposium}

Key themes and subthemes emerged from symposium discussions.

No consensus definition of SIC. "SIC" is a relatively new concept in the academic literature. As a working definition to spark discussion, we proposed at the beginning of the symposium that SIC "is a discussion between a clinician and a seriously ill patient (or surrogate) that focuses on values, goals, prognosis, and/or care preferences/care planning." Participants discussed the lack of an agreed-upon conceptual framework to distinguish this from other activities, including ACP and goals of care discussions. Furthermore, the lack of consensus perpetuates disagreements about who on a care team can lead SIC. For example, some argued that lay facilitators could be trained to engage individuals in SIC, where others felt that SIC should be initiated by clinicians with the authority to communicate prognosis.

Methodological challenges related to measuring communication and its outcomes. Participants highlighted several challenges inherent to measuring SIC and its outcomes. First, attempts to articulate a quality measurement framework for SIC must match measures to their intended purpose. Measures are used for quality improvement (QI), research, and accountability. The performance characteristics of measures utilized for one purpose will differ from measures used for another. For example, a process measure used for accountability purposes, such as the presence of an advance care plan, would be held to a different standard than one used for QI purposes, and would need to meet these four criteria: strong evidence of its impact on patient outcomes, accuracy in capturing that the care process has occurred, proximity to the desired patient outcomes, and little or no unintended consequences. ${ }^{25,26}$ Second, there may be no known or feasible interventions to improve a given care indicator; or data may be too difficult to collect or use within the normal clinical care flow such that it is unlikely to lead to improvements at scale. For example, bereaved caregiver surveys about the quality of care tend to have low response rates and may not be specifically responsive to SIC alone.

Third, the degree to which serious illness care outcomes are attributable to communication is unclear. That care experience in serious illness is known to differ by setting ${ }^{27}$ highlights how little is known about the mechanisms by and extent to which SIC shapes outcomes. ${ }^{19}$

Fourth, documentation in the electronic health record tends to incompletely reflect spoken communication, complicating communication process measurement. ${ }^{28,29}$ Participants noted that efforts to improve documentation must consider feasibility challenges, such as clinician time constraints, and questions of accountability in team-based settings (i.e., who is responsible for documenting such communication?).

Finally, implementation of measures may result in unintended consequences. ${ }^{30}$ For example, participants expressed concern that efforts to standardize SIC quality metrics might result in approaches to engaging patients and families that focus on document completion rather than conversation initiation. $^{31}$ In addition, measures taken up as part of accountability schemes can be reduced to "tick-box" exercises that reflect only perfunctory changes in care processes and thereby miss opportunities to know if meaningful communication occurred. As for outcomes, patients with serious illness may experience burden due to patient-reported outcome measurement.

Underutilization of measurement technologies. Measuring SIC quality and impact currently relies on chart review or survey instruments, which present analytical and collection challenges, respectively. However, participants agreed that the electronic health record (EHR) is an underutilized source of data. Participants considered novel measurement strategies, including natural language processing and machine learning. Researchers are using this technology to identify ACP documentation in large unstructured data sets. ${ }^{32}$ Developments in open note platforms and patient portals, which enable direct patient contribution to the medical record, may enable more robust collection of patientreported outcome measures. ${ }^{33,34}$ Such tools make it possible to evaluate data across multiple platforms and may assist in connecting communication to outcomes that survey data may not capture. The nascent state of development of these tools means that they remain an unproven, but promising strategy for assessing the quality of communication in the future.

Measure development and dissemination opportunities. Symposium discussion highlighted the importance of relying on quality measure processes that are already tied to both QI and accountability, such as the CAHPS family of measures. ${ }^{35}$ While most current CAHPS measures (Table 1) are setting specific, that is, tied to hospital, home health, hospice, or long-term care encounters, future CAHPS instruments have the potential to assess care experiences for persons with serious illness or their caregivers across a range of settings. Research studies have used the "Quality of communication" scale, ${ }^{36}$ which has been shown to be responsive to several communication interventions. ${ }^{37-39}$ In addition, national quality and accreditation bodies such as the National Consensus Project, NQF, and the National Center for Quality Assurance (NCQA) are actively promoting and/ or developing standards, as well as process and outcome 
Table 1. Examples of Existing CommunicationRelated Consumer Assessment of Health care Provider and System Measures, by Setting

\begin{tabular}{|c|c|}
\hline Multiple & $\begin{array}{l}\text { How often did doctors explain things in a } \\
\text { way you could understand? }\end{array}$ \\
\hline Multiple & $\begin{array}{l}\text { How often did doctors treat you with } \\
\text { courtesy and respect? }\end{array}$ \\
\hline Hospital & $\begin{array}{l}\text { Staff took my preferences and those of my } \\
\text { family or caregiver into account in } \\
\text { deciding what my health care needs } \\
\text { would be when I left. }\end{array}$ \\
\hline Hospice & $\begin{array}{l}\text { How often did the hospice team keep you } \\
\text { informed about your family member's } \\
\text { condition? }\end{array}$ \\
\hline Multiple & $\begin{array}{l}\text { How often did doctors listen carefully to } \\
\text { you? }\end{array}$ \\
\hline $\begin{array}{l}\text { Cancer } \\
\quad \text { supplement }\end{array}$ & $\begin{array}{l}\text { Did a doctor or other health professional } \\
\text { at this cancer center involve you in } \\
\text { decisions about your cancer treatment } \\
\text { as much as you wanted? }\end{array}$ \\
\hline $\begin{array}{l}\text { Cancer } \\
\quad \text { supplement }\end{array}$ & $\begin{array}{l}\text { Since your cancer was diagnosed, did a } \\
\text { doctor or other health care professional } \\
\text { at this cancer center ask for your } \\
\text { opinion about each choice of cancer } \\
\text { treatment, including the treatments you } \\
\text { did not get? }\end{array}$ \\
\hline
\end{tabular}

measures to assess and improve SIC quality. Participants acknowledged that the development and dissemination of measures take years and must be balanced against the need for systems to measure QI efforts now.

\section{Measurement gap analysis}

We identified gaps between measurement constructs highlighted by participants and those currently represented by existing quality frameworks (e.g., American Association of Hospice and Palliative Medicine [AAHPM] Measuring What Matters), quality measures, or research instruments. Table 2 provides an example of measures in each gap category.

\section{Post-symposium survey}

Survey respondents varied in their prioritization of measurement constructs; however, significant agreement (>80\% strongly agree or agree on a 7-point Likert scale) about several aspects of quality measurement relevant to SIC informed our recommendations presented below.

\section{Challenges, Recommendations, and Future Research}

We convened an expert stakeholder symposium and subsequently surveyed participants to consider challenges, opportunities, priorities, and strategies to improve quality measurement specific to SIC. Findings from these efforts reflect several areas of agreement and unresolved tensions, and inform recommendations for stakeholder groups to help advance the states of science and implementation of quality measures relevant to SIC.

\section{A shared definition of SIC will guide measurement approaches}

Participants raised four inter-related issues that impact quality measurement of SIC: of what SIC consists and when
Table 2. Categories and EXamples of Measurement GaPS

\begin{tabular}{|c|c|}
\hline $\begin{array}{l}\text { Quality measures } \\
\text { exist, but are not } \\
\text { included in } \\
\text { relevant measure } \\
\text { sets for seriously } \\
\text { ill patients }\end{array}$ & $\begin{array}{l}\text { - Documentation of goals or wishes } \\
\text { in structured, accessible location } \\
\text { in health record (process) } \\
\text { - Satisfaction with prognostic } \\
\text { communication (patient } \\
\text { experience): percentage of } \\
\text { patients and family/caregivers } \\
\text { within health facilities or systems } \\
\text { that understand and are satisfied } \\
\text { with provider communication } \\
\text { about prognosis. }{ }^{54}\end{array}$ \\
\hline $\begin{array}{l}\text { Research } \\
\text { instruments } \\
\text { exist, but have } \\
\text { not undergone } \\
\text { development as } \\
\text { quality measures }\end{array}$ & $\begin{array}{l}\text { - Clinician training (structure): } \\
\text { proportion of clinicians who care } \\
\text { for seriously ill patients, who } \\
\text { complete training on high quality, } \\
\text { informed communication about } \\
\text { values, goals, and care } \\
\text { preferences. }{ }^{5} \text { - Quality of communication } \\
\text { (patient/family experience): A } \\
\text { 13-item questionnaire with } 7 \\
\text { items focused on communication } \\
\text { about serious illness. } \\
\text { - Heard and understood (patient } \\
\text { experience) } 56\end{array}$ \\
\hline $\begin{array}{l}\text { Neither research } \\
\text { instruments nor } \\
\text { quality measures }_{\text {exist }^{\mathrm{a}}}\end{array}$ & $\begin{array}{l}\text { - Timely information (patient } \\
\text { experience) } \\
\text { - Caregiver unmet needs assessed } \\
\text { (process) } \\
\text { - Clinician experience (outcomes) }\end{array}$ \\
\hline
\end{tabular}

${ }^{\mathrm{a}} \mathrm{Gap}$ between what stakeholders proposed in the symposium and what currently exists. Such measures would need to undergo further development to know if they are feasible, reliable, and so on.

it occurs, why it is important and distinct, who should initiate it, and for whom?

First, absence of a shared definition of SIC limits the applicability of measures. SIC is a relatively new concept and it remains unclear to many how it fits in the broader landscape of ACP or goals of care communication. Experts define ACP as "a process that supports adults at any age or stage of health in understanding and sharing their personal values, life goals, and preferences regarding future medical care." 40 As such, SIC may be considered a type of ACP for individuals with serious illness.

Second, ACP may hold particular urgency and importance for patients with serious illness because they are likely to face medical decisions that necessitate patient-centered communication about their goals and values. While symposium participants agreed that such communication in the context of serious illness is distinct from other forms of ACP, their views differed on the minimum standard to identify such communication for the purpose of measurement. A large majority indicated that documentation of current care or treatment preferences should be included as a standard. Of note, documentation of treatment preferences is required under the Hospice Quality Reporting Program and is considered to be "topped out," and therefore of limited use for differentiating providers. ${ }^{41}$ This is evidence that regulatory requirements have the potential to shape clinician and system behavior. This uncontroversial indicator is likely to be 
present whether or not high-quality communication occurred. A majority also felt that documentation of personal values and documentation of prognostic understanding/awareness should indicate conversation completion.

Third, some participants advocated for a role for lay facilitators to enable SIC. A recent intervention using a lay facilitator demonstrated statistically significant differences in goals of care documentation, overall rating of providers on a CAHPS measure, increased utilization of hospice in the last 30 days, and decreased hospital, emergency department utilization, and overall health care spending. ${ }^{42}$ This approach holds promise, yet communication of prognosis was outside the scope of this intervention. Other participants proposed that SIC should be clinician led because they are best positioned to help patients understand their prognosis and treatment options and can most effectively translate the conversation into care planning. While employing lay health workers may be less costly than training and incentivizing clinicians for this task, questions remain about their relevant effectiveness that research may help elucidate.

Finally, measures of SIC are subject to uncertainty about how to define the population in need, the so-called "denominator problem." 43 Recent efforts are adding increasing clarity to definitions of who is seriously ill. ${ }^{3}$ While systems may choose criteria by which to define their seriously ill population, lack of consistent populations undermines certain measurement purposes, especially those developed for accreditation or accountability. Others have identified this as a key research priority in palliative care quality measurement. ${ }^{44}$

We propose that SIC is an ACP activity with potentially distinct processes and outcomes. Sudore recently described findings from a Delphi panel formed to reach consensus regarding ACP outcomes. ${ }^{40}$ Similarly, members of the Canadian Researchers at the End of Life Network (CARENET) and the Audit of Communication, CarE Planning and documentation (ACCEPT) Study team, convened a Delphi panel to develop a conceptual framework and quality indicators to improve end-of-life communication and decision making, ${ }_{46}$ which they then sought to validate in a multicenter study. ${ }^{46}$

SIC, other ACP activities, and goals of care discussions share common features, may inform each other, and may result in common outcomes. Therefore, it is unsurprising to find overlap in the way stakeholders propose to measure them, including the processes involved. However, in comparison to ACP, as broadly conceptualized, and goals of care discussions in the hospital, SIC specifically aims to improve care and experience over the trajectory of serious illness, not just at the end of life.

Accordingly, we would suggest that measurement moves beyond exclusive attention to the naming of surrogates (as in ACP) or the documentation of decisions regarding lifesustaining treatments (as in discussions about specific goals of care or end-of-life treatment preferences) to include the structures and processes that reinforce prognostic communication according to patient's preferences, patient-centered communication about values and goals, and shared decision making. ${ }^{20}$ Since these specific processes may have greatest urgency for patients with serious illness, systematic identification of patients at high risk of dying is a critical structural indicator that results in a different denominator than that for ACP (everyone) or goals-of-care discussions (which may be best distinguished by their focus on a clear decision-making opportunity). Keeping these challenges in mind, we make the following recommendations; we propose that systems measure SIC by its inclusion of, or reference to, prognostic information, personal values or goals, or both.

\section{Structures and processes should reinforce the delivery of high-quality SIC and related outcomes}

Structural measures evaluate the attributes of a system that enable care processes. Participants highlighted the need for systems to reliably identify seriously ill patients, train and coach clinicians toward improved communication, assure that clinicians elicit and document information regarding patients' values, goals, and care preferences, and ensure that such documentation is accessible at multiple points of care. Health systems have demonstrated the feasibility of implementing such structures. ${ }^{47}$ These measures have a high degree of face validity. While the degree to which the measures consistently facilitate processes to occur remains unknown, communication processes are likely to occur only in an $\mathrm{ad}$ hoc manner if such structures are absent.

Process measures assess the extent and occurrence of care delivered to patients. Participants prioritized process measures that reflect the importance of named surrogate decision makers and documentation of values, goals, and care preferences in a location that is accessible at multiple points of care. As with the proposed structural measures, these process measures may, in some cases, lack evidence of association with patient outcomes. However, they are actionable, feasible, and face valid. ${ }^{47,48}$

Symposium participants value goal-concordant care as an outcome both relevant to and dependent on SIC. This construct is among the most challenging to measure ${ }^{49,50}$ and some feel that it cannot be feasibly measured for any purpose. Some researchers have assessed patients' perceptions of whether the care they are receiving is goal concordant in the research setting. ${ }^{38}$ Survey respondents favored a bereavement measure of goal concordance. The Veterans Affairs Bereaved Family Survey uses such a measure and research instruments, including the National Health and Aging Trends Study, and multiple mortality follow-back studies have used this approach. ${ }^{27,51,52}$ A recent review of goal-concordance measurement promoted this approach. ${ }^{49}$ Still, while it can be incorporated into bereavement surveys, response rates of such surveys have been low in some settings ${ }^{13}$ and do not reflect the perspective of the patient himself/herself. It is also not clear to what degree systems exhibit enough variability in this measure to make it useful for quality measurement or improvement.

Existing patient experience measurement constructs vary in their potential applicability. Some suggest promise for inclusion in national survey instruments, including the degree to which a patient feels heard and understood, the degree to which patients receive as much information as is desired, and the degree to which patients understand and are satisfied with prognostic communication. Some patient experience measures are used in research instruments and should be further tested for inclusion in quality measure sets. Patient experience measures place demands on patients and their caregivers and may be limited by low response rates among serious illness populations. Participants prioritized patients 
feeling cared for and perceiving that information is accessible to relevant parties at the right time. Among those constructs for which there are no research instruments or quality measures, participant survey respondents prioritized measures that assess patients' valuation of how well the care team understands their priorities and adequately supports their decision making. In addition, we identified measurement constructs that assess clinician experience of SIC, because it can positively or negatively affect clinicians themselves and may hinder their willingness to engage other patients in these important and potentially difficult conversations.

\section{Health systems have an opportunity to use a core set of measures in QI and innovation}

Health systems cannot wait for quality measure development to initiate efforts to improve the occurrence and quality of SIC because of its clear value and critical importance to patients and their families. Private and government health systems, such as the Veterans Affairs, have begun to disseminate QI initiatives focused on SIC. Evidence suggests that QI interventions can improve occurrence and quality of communication for seriously ill patients. ${ }^{53}$

For systems implementing communication as quality initiatives, we recommend that systems consider a set of example structural, process, and outcome measures (Table 3). These measures have been piloted in several health systems, in the United States, United Kingdom, and Canada, as part of implementation of the serious illness care program.

\section{Health IT vendors play a critical role in enabling quality measurement for health systems and researchers}

Electronic health records should support meaningful communication and reduce the burden of measurement and data capture on clinicians and systems. In line with recent recommendations derived from a national panel of content experts (some of whom participated in our symposium), ${ }^{29}$ we recommend that EHR vendors develop base modules for ACP and SIC that allow for structured and unstructured data capture around patient goals, values, and treatment preferences, as well as documentation of surrogate decision makers. This information is not currently required to be captured or exchanged (i.e., by the U.S. Core Data for Interoperability [USCDI] or Continuity of Care [CCD]). Vendor participants suggested that any change in centralized EHR structures would need to be supported by use in a quorum of health systems.

\section{Limitations}

While our review of existing quality measurement domains and instruments was extensive, it was not exhaustive. While we surveyed participants following the symposium as a form of participant checking, and invited them to review this article, our synthesis from many important discussion points necessarily introduces editorial bias into this process. This group of symposium participants did not include patients, caregivers, or formal advocates on their behalf. While several participants shared personal experiences in navigating the serious illness care landscape and many clinicians provided an empathic view of the patients and families for whom they cared, participants felt conflicted about prioritizing measurement constructs for patient experience outcomes in the absence of patient participation.

Notably, many of the constructs discussed, and all those for which there are existing research instruments or quality measures, emerged from processes that involved patients. We view patient and family engagement as a critical step in the process of instrument and measure development. Finally, the strength of the recommendations presented reflects the limitations inherent to our methodological approach. In many instances, they reflect expert opinion or consensus only.

Table 3. Example Serious Illness Communication Measures for Health Systems

\begin{tabular}{|c|c|c|}
\hline Type & Description & Example \\
\hline Structures & $\begin{array}{l}\text { Assesses the organizational } \\
\text { capacity to systematically } \\
\text { deliver SIC }\end{array}$ & $\begin{array}{l}\text { - Proportion of targeted clinicians trained in SIC } \\
\text { - Presence of a systematic process to prospectively identify patients with } \\
\text { serious illness } \\
\text { - Presence of accessible documentation template for SIC in EHR. }\end{array}$ \\
\hline Process & $\begin{array}{l}\text { Determines if SIC is reliably } \\
\text { offered and/or delivered to } \\
\text { patients with serious illness }\end{array}$ & $\begin{array}{l}\text { - Number (or percent) of seriously ill patients with a documented } \\
\text { conversation about values, goals, prognosis, and/or care preferences (or } \\
\text { documented refusal) } \\
\text { - Frequency, timing, and comprehensiveness of documented SIC in } \\
\text { deceased patients }\end{array}$ \\
\hline Experience & $\begin{array}{l}\text { Evaluates experience of care } \\
\text { from multiple perspectives }\end{array}$ & $\begin{array}{l}\text { - Patient-reported experience of SIC } \\
\text { - Clinician experience of serious illness communication in training and in } \\
\text { practice }\end{array}$ \\
\hline Outcomes & $\begin{array}{l}\text { Evaluates relevant outcomes } \\
\text { from multiple perspectives }\end{array}$ & $\begin{array}{l}\text { - Patient- and family-reported outcomes (e.g., anxiety, depression, and } \\
\text { quality of life) } \\
\text { - Goal-concordant care (ideally from a bereaved family survey) } \\
\text { - Quality of care at the end of life in the last place of care (bereaved family } \\
\text { survey) } \\
\text { - Care utilization at the end of life (e.g., hospice use and length of stay, } \\
\text { hospitalizations, readmissions, intensive care unit, chemotherapy, } \\
\text { surgery, and emergency department use) } \\
\text { - Costs of care }\end{array}$ \\
\hline
\end{tabular}

EHR, electronic health record; SIC, serious illness communication. 
Table 4. Recommended Stakeholder Actions to Support Quality and Accountability FOR SERIOUs Illness COMMUNICATION

\begin{tabular}{l} 
Stakeholder category \\
\hline $\begin{array}{l}\text { Health systems and quality } \\
\text { improvement organizations }\end{array}$
\end{tabular}

improvement organizations

Quality measure developers

Researchers

Health IT vendors

\section{Actions}

1. Measure the structures and processes that support the delivery of serious illness communication, including clinician training and conversation documentation in a structured and accessible EHR template.

2. Consider measuring outcomes that can be feasibly extracted from routinely collected data or incorporated into existing workflows.

1. A national accountability framework for programs caring for patients with serious illness should include a precisely defined, reliable approach to measuring communication between clinicians and patients.

2. CAHPS ${ }^{\circledR}$ surveys assessing care in seriously ill populations should be developed, and should consider, including the following patient experience measurement constructs, the following:

a. The patient feels "heard and understood";

b. The patient receives as much information as he/she wants;

c. The patient understands and has needs met for prognostic communication.

1. Researchers focused on communication interventions for patients with serious illness should work to agree on a core set of process and outcome measures to understand the relative impact of these interventions.

2. Because current instruments appear insufficient to capture the impact of serious illness communication among multiple stake holders, we recommend the development and testing of instruments to assess the following:

a. Patient assessment of the care team's understanding of their goals, values, and priorities;

b. Patient assessment of the adequacy of support in decision making;

c. Clinician assessment of self-efficacy in communication; and

d. Clinician assessment of support to have high-quality communication.

3. Researchers should urgently focus on developing novel techniques to extract useful structured and unstructured quality data from EHRs to support scientific and quality improvement efforts.

1. Vendors should develop SIC modules that feature the following characteristics: a. They should facilitate clinicians' data entry from the site of usual documentation, because any additional work required for data entry is likely to result in noncompletion;

b. They should populate a "single source of truth," the one place in the EHR where one can reliably find up-to-date information regarding patient's goals, preferences, and decisions;

c. They should be interoperable across EHRs because seriously ill patients are particularly vulnerable to the communication failures that result from noninteroperability.

- Vendors should work with systems to create opportunities for direct engagement with patients and surrogates, such that they might input relevant information themselves.

CAHPS, Consumer Assessment of Healthcare Providers and Systems; IT, information technology.

\section{Conclusion}

Patients, clinicians, and health systems increasingly align around the importance of high-quality communication in serious illness. This article reports on an initial effort to define the most meaningful constructs and outcomes of SIC to drive QI. Our process highlighted both the need for robust metrics to continue to drive the change that has begun, as well as the considerable work that remains to be done. We have an urgent need to include the patient voice in better defining key metrics. Partnerships among health systems, payers, and Health IT vendors can contribute to the development and testing of these new metrics. Just as every clinician has responsibility for ensuring that their patients with serious illness have the opportunity to articulate and share their goals, values, and priorities, each stakeholder group bears respon- sibility for facilitating measurement of this critical process and its related outcomes (Table 4).

\section{Acknowledgments}

We wish to acknowledge the contribution of several members of the Ariadne Labs staff, including Jane Kavanagh, Lauren Nisotel, April Kim, Francine Maloney, Natalie Henrich, Sharelle Davis, Caroline Grogan, Evan Benjamin and Elizabeth Wilson. We would also like to thank Betty Ferrell and Amy Berman for their thoughtful review of the white paper.

\section{Funding Information}

The authors wish to express their gratitude to the Cambia Health Foundation for providing funding to support both the 
symposium in quality metrics in serious illness communication and the subsequent writing of this white paper; as well as the Richard A Cantor Fund for Communications Research in Palliative Care for their support of the symposium. Dr. Sanders and Dr. Paladino also received or receive funding from the Cambia Health Foundation Sojourns Scholars Program.

\section{Author Disclosure Statement}

No competing financial interests exist.

\section{Supplementary Material}

Supplementary Table S1

\section{References}

1. Simpson M, Buckman R, Stewart M, et al.: Doctor-patient communication: the Toronto consensus statement. BMJ 1991;303:1385-1387.

2. Bernacki RE, Block SD; American College of Physicians High Value Care Task F: Communication about serious illness care goals: A review and synthesis of best practices. JAMA Intern Med 2014;174:1994-2003.

3. Kelley AS, Bollens-Lund E: Identifying the population with serious illness. The "denominator" challenge. J Palliat Med 2018;21:S7.

4. Detering KM, Hancock AD, Reade MC, Silvester W: The impact of advance care planning on end of life care in elderly patients: Randomised controlled trial. BMJ 2010; 340:c1345.

5. Mack JW, Weeks JC, Wright AA, et al.: End-of-life discussions, goal attainment, and distress at the end of life: Predictors and outcomes of receipt of care consistent with preferences. J Clin Oncol 2010;28:1203-1208.

6. Wright AA, Zhang B, Ray A, et al.: Associations between end-of-life discussions, patient mental health, medical care near death, and caregiver bereavement adjustment. JAMA 2008;300:1665-1673.

7. Zhang B, Wright AA, Huskamp HA, et al.: Health care costs in the last week of life: Associations with end-of-life conversations. Arch Intern Med 2009;169:480-488.

8. Weiner JS, Cole SA: Three principles to improve clinician communication for advance care planning: Overcoming emotional, cognitive, and skill barriers. J Palliat Med 2004; 7:817-829.

9. Meier DE, Back AL, Morrison RS: The inner life of physicians and care of the seriously ill. JAMA 2001;286:30073014.

10. Grunfeld E, Whelan TJ, Zitzelsberger L, et al.: Cancer care workers in Ontario: Prevalence of burnout, job stress and job satisfaction. CMAJ 2000;163:166-169.

11. Leung JM, Udris EM, Uman J, Au DH: The effect of endof-life discussions on perceived quality of care and health status among patients with COPD. Chest 2012;142:128-133.

12. Street RL, Jr., Makoul G, Arora NK, Epstein RM: How does communication heal? Pathways linking clinicianpatient communication to health outcomes. Patient Educ Couns 2009;74:295-301.

13. Bernacki R, Paladino J, Neville BA, et al.: Effect of the serious illness care program in outpatient oncology: A cluster randomized clinical trial. JAMA Intern Med 2019; 179:751-759.
14. Billings JA, Bernacki R: Strategic targeting of advance care planning interventions: The Goldilocks phenomenon. JAMA Intern Med 2014;174:620-624.

15. Lorenz KA, Rosenfeld K, Wenger N: Quality indicators for palliative and end-of-life care in vulnerable elders. J Am Geriatr Soc 2007;55 Suppl 2:S318-S326.

16. Global Palliative Care Quality Alliance: www.gpcqa.org

17. Palliative Care Quality Network: www.pcqn.org

18. Measuring What Matters: American Academy of Hospice and Palliative Medicine. www.aahpm.org/quality/MeasuringWhat-Mattters. (Last accessed March 15, 2017).

19. Tulsky JA, Beach MC, Butow PN, et al.: Research agenda for communication in serious illness: A review. JAMA Intern Med 2017;177:1361-1366.

20. Teno JM, Price RA, Makaroun LK: Challenges of measuring quality of community-based programs for seriously ill individuals and their families. Health Aff (Millwood) 2017;36:1227-1233.

21. Henry M, Hudson Scholle S, Briefer French J: Accountability for the quality of care provided to people with serious illness. J Palliat Med 2018;21(S2):S68-S73.

22. Donabedian A: Quality assurance. Structure, process and outcome. Nurs Stand 1992;7(11 Suppl QA):4-5.

23. Sikka R, Morath JM, Leape L: The quadruple aim: Care, health, cost and meaning in work. BMJ Qual Saf 2015;24: 608-610.

24. Ferrell B, Connor SR, Cordes A, et al.: The national agenda for quality palliative care: The National Consensus Project and the National Quality Forum. J Pain Symptom Manage 2007;33:737-744.

25. Chassin MR, Loeb JM, Schmaltz SP, Wachter RM: Accountability measures-using measurement to promote quality improvement. N Engl J Med 2010;363:683-688.

26. Teno JM, Montgomery R, Valuck T, et al.: Accountability for community-based programs for the seriously ill. J Palliat Med 2018;21(S2):S81-S87.

27. Teno JM, Clarridge BR, Casey V, et al.: Family perspectives on end-of-life care at the last place of care. JAMA 2004;291:88-93.

28. Geerse OP, Lamas DJ, Sanders JJ, et al.: A qualitative study of serious illness conversations in patients with advanced cancer. J Palliat Med 2019;22:773-781.

29. Lamas D, Panariello N, Henrich N, et al.: Advance care planning documentation in electronic health records: Current challenges and recommendations for change. J Palliat Med 2018;21:522-528.

30. Casalino LP: The unintended consequences of measuring quality on the quality of medical care. N Engl J Med 1999; 341:1147-1150.

31. Tolle SW, Teno, J.M: Counting POLST form completion can hinder quality. In: Health Affairs Blog. Health Affairs, 2018.

32. Avati AJ, K; Harman, S; Downing, L; et al.: Improving palliative care with deep learning. BMC Med Inform Decis Mak 2018;18(Suppl 4):122.

33. Delbanco T, Walker J, Darer JD, et al.: Open notes: Doctors and patients signing on. Ann Intern Med 2010;153:121-125.

34. Esch T, Mejilla R, Anselmo M, et al.: Engaging patients through open notes: An evaluation using mixed methods. BMJ Open 2016;6:e010034.

35. Phipps E, True G, Harris D, et al.: Approaching the end of life: Attitudes, preferences, and behaviors of AfricanAmerican and white patients and their family caregivers. J Clin Oncol 2003;21:549-554. 
36. Engelberg R, Downey L, Curtis JR: Psychometric characteristics of a quality of communication questionnaire assessing communication about end-of-life care. J Palliat Med 2006;9: 1086-1098.

37. Curtis JR, Engelberg RA, Nielsen EL, et al.: Patientphysician communication about end-of-life care for patients with severe COPD. Eur Respir J 2004;24:200-205.

38. Curtis JR, Downey L, Back AL, et al.: Effect of a patient and clinician communication-priming intervention on patient-reported goals-of-care discussions between patients with serious illness and clinicians: A randomized clinical trial. JAMA Intern Med 2018;178:930-940.

39. Curtis JR, Back AL, Ford DW, et al.: Effect of communication skills training for residents and nurse practitioners on quality of communication with patients with serious illness: A randomized trial. JAMA 2013;310:2271-2281.

40. Sudore RL, Lum HD, You JJ, et al.: Defining advance care planning for adults: A consensus definition from a multidisciplinary Delphi panel. J Pain Symptom Manage 2017.

41. Anhang Price R, Elliott MN: Measuring patient centeredness of care for seriously ill individuals: Challenges and opportunities for accountability initiatives. J Palliat Med 2018;21:5-28.

42. Patel MI, Sundaram V, Desai M, et al.: Effect of a lay health worker intervention on goals-of-care documentation and on health care use, costs, and satisfaction among patients with cancer: A randomized clinical trial. JAMA Oncol 2018;4:1359-1366.

43. Teno JM, Coppola KM: For every numerator, you need a denominator: A simple statement but key to measuring the quality of care of the "dying". J Pain Symptom Manage 1999; 17:109-113.

44. Dy SM, Herr K, Bernacki RE, et al.: Methodological research priorities in palliative care and hospice quality measurement. J Pain Symptom Manage 2016;51:155162.

45. Sinuff T, Dodek P, You JJ, et al.: Improving end-of-life communication and decision making: The development of a conceptual framework and quality indicators. J Pain Symptom Manage 2015;49:1070-1080.

46. Heyland DK, Dodek P, You JJ, et al.: Validation of quality indicators for end-of-life communication: Results of a multicentre survey. CMAJ 2017;189:E980-E989.

47. Lakin JR, Koritsanszky LA, Cunningham R, et al.: A systematic intervention to improve serious illness communication in primary care. Health Aff (Millwood) 2017;36: $1258-1264$.
48. Paladino J, Bernacki R, Neville BA, et al.: Evaluating an intervention to improve communication between oncology clinicians and patients with life-limiting cancer: A cluster randomized clinical trial of the serious illness care program. JAMA Oncol 2019;5:801-809.

49. Sanders JJ, Curtis JR, Tulsky JA: Achieving goalconcordant care: A Conceptual model and approach to measuring serious illness communication and its impact. J Palliat Med 2018;21(S2):S17-S27.

50. Unroe KT, Hickman SE, Torke AM, Group ARCW: Care consistency with documented care preferences: Methodologic considerations for implementing the "Measuring What Matters" quality indicator. J Pain Symptom Manage 2016;52:453-458.

51. Khandelwal N, Curtis JR, Freedman VA, et al.: How often is end-of-life care in the United States inconsistent with patients' goals of care? J Palliat Med 2017;20:1400-1404.

52. Pasman HR, Kaspers PJ, Deeg DJ, Onwuteaka-Philipsen BD: Preferences and actual treatment of older adults at the end of life. A mortality follow-back study. J Am Geriatr Soc 2013;61:1722-1729.

53. Fawole OA, Dy SM, Wilson RF, et al.: A systematic review of communication quality improvement interventions for patients with advanced and serious illness. J Gen Intern Med 2013;28:570-577.

54. Yabroff KR, Mandelblatt JS, Ingham J: The quality of medical care at the end-of-life in the USA: Existing barriers and examples of process and outcome measures. Palliat Med 2004;18:202-216.

55. Bernacki R, Hutchings M, Vick J, et al.: Development of the Serious Illness Care Program: A randomised controlled trial of a palliative care communication intervention. BMJ Open 2015;5:e009032.

56. Gramling R, Stanek S, Ladwig S, et al.: Feeling heard and understood: A patient-reported quality measure for the inpatient palliative care setting. J Pain Symptom Manage 2016;51:150-154.

Address correspondence to:

Justin J. Sanders, MD, MSc

Department of Psychosocial Oncology and Palliative Care

Dana-Farber Cancer Institute 450 Brookline Avenue LW670

Boston, MA 02215

E-mail: justin_sanders@dfci.harvard.edu 